\title{
Type I Gaucher disease with exophthalmos and pulmonary arteriovenous malformation Chun-An Chen ${ }^{1}$, Nelson LS Tang 3 , Yin-Hsiu Chien ${ }^{1,2}$, Wei-Min Zhang ${ }^{3}$, Jou- Kou Wang ${ }^{1}$ and Wuh-Liang Hwu*1,2
}

\begin{abstract}
Address: ${ }^{1}$ Departments of Pediatrics, National Taiwan University Hospital and National Taiwan University College of Medicine, Taipei, Taiwan, ${ }^{2}$ Medical Genetics, National Taiwan University Hospital and National Taiwan University College of Medicine, Taipei, Taiwan and ${ }^{3}$ Department of Chemical Pathology, The Chinese University of Hong Kong, Hong Kong

Email: Chun-An Chen - chenca@ntu.edu.tw; Nelson LS Tang - nelsontang@cuhk.edu.hk; Yin-Hsiu Chien - chienyh@ha.mc.ntu.edu.tw; WeiMin Zhang - nelsontang@cuhk.edu.hk; Jou-Kou Wang - jkw@ha.mc.ntu.edu.tw; Wuh-Liang Hwu* - hwu@ha.mc.ntu.edu.tw

* Corresponding author
\end{abstract}

Published: 09 June 2005

BMC Medical Genetics 2005, 6:25 doi:10.1/86/147/-2350-6-25
Received: 17 November 2004

Accepted: 09 June 2005

This article is available from: http://www.biomedcentral.com/I47I-2350/6/25

(c) 2005 Chen et al; licensee BioMed Central Ltd.

This is an Open Access article distributed under the terms of the Creative Commons Attribution License (http://creativecommons.org/licenses/by/2.0), which permits unrestricted use, distribution, and reproduction in any medium, provided the original work is properly cited.

\begin{abstract}
Background: Gaucher disease type I, the non-neuropathic type, usually presents in adulthood with hepatosplenomegaly. We report here an adult with type I Gaucher disease presented with unusual and severe clinical manifestations.

Case presentation: Hepatosplenomegaly, bone crisis and fractures occurred at early childhood, and splenectomy was performed at the age of 5. Exophthalmos with increase in retrobulbar space was noted when the patient was 30. Cerezyme infusion started at the age of 32; but unfortunately, pulmonary arteriovenous malformation with dyspnea and hypoxemia was found two years later. Gene analysis revealed V375L/L444P mutations in the $\beta$-glucocerebrosidase gene.

Conclusion: Although both eye and lung diseases have been associated with Gaucher disease, this is the first reported demonstration of exophthalmos and pulmonary arteriovenous malformation in the same patient. This case may therefore present an extremely severe and unusual form of type I Gaucher disease.
\end{abstract}

\section{Backgound}

Gaucher disease is a lysosomal storage disorder caused by a recessively inherited deficiency of glucocerebrosidase activity, which causes an accumulation of sphingolipid glucosylceramide in cells of the reticulo-endothelial systems [1]. The "Gaucher cells" can be found in the spleen, liver, bone, and central nerve system in affected individuals, causing hepatosplenomegaly, anemia, thrombocytopenia and skeletal diseases [1]. Three clinical forms of the disease have been described, based on the absence (type I) or the presence (types II and III) of neurological involvement in addition to the visceral findings [1].
Pulmonary involvement, with Gaucher cell infiltration of the alveolar or interstitial spaces [2], may be more common than previously thought, but clinically significant lung disease is still rare [3]. Pulmonary arteriovenous shunting has been implicated as the etiology of hypoxemia in patients with long-standing liver disease related to Gaucher disease $[4,5]$. Pulmonary arteriovenous malformation (AVM) in Gaucher disease, however, has not been reported in the English literature. Ocular manifestations of type I Gaucher disease include infiltration of the retina, conjunctiva and uvea with visual loss [6-8]. However, exophthalmos related to Gaucher disease has also not 
been described. Here we report an adult with Gaucher disease complicated with these two unusual manifestations, exophthalmos and pulmonary AVM.

\section{Case presentation}

This 34-year-old woman was a case of Gaucher disease type I with initial presentation of hepatosplenomegaly and severe bone diseases including fractures of the lower extremities and bone crisis at childhood. She was the second of a pair of twins. Her twin sister and another younger sister are both affected. There is no consanguinity in the family. She underwent splenectomy at age 5 years due to persistent thrombocytopenia, but the diagnosis of Gaucher disease was established only after a bone marrow examination at age 11 years. Her leukocytes $\beta$-glucocerebrosidase activity checked at age 26 years was $1.56 \mathrm{nmol} /$ $\mathrm{mg} / \mathrm{h}$ (normal: $>28.42 \mathrm{nmol} / \mathrm{mg} / \mathrm{h}$ ). At that time, she had severe bone deformities, hepatomegaly, anemia, clubbing fingers and toes, but pink lips. There was no audible heart murmur, and her breathing sound was clear. Her liver size was measured $5 \mathrm{~cm}$ below subcostal margin at right midclavicular line, and neither spider angiomata nor superficial vein engorgement was found. Hemogram revealed a platelet count of $103 \times 10^{9} / \mathrm{L}$ and hemoglobin level of 9.6 $\mathrm{mg} / \mathrm{dL}$. DNA analysis of this patient and her two affected siblings all revealed a V375L/L444P genotype of the $\beta$-glucocerebrosidase gene.

The patient complained of bilateral orbital pain with gradual protrusion of eyes since 30 years old. Thyroid function tests, including T3, T4, thyroid-stimulating hormone and free T4, showed normal results. Ophthalmologic examinations failed to reveal any specific findings related to the exophthalmos. Magnetic resonance imaging (MRI) of the eyes revealed increases in retrobulbar space with fat-like density and mild hypertrophy of extra-ocular muscles (Fig. 1A). She received enzyme replacement therapy (ERT) with imiglucerase (Cerezyme) at a dose of 60 $\mathrm{U} / \mathrm{kg}$ every two weeks since 32 years old. Her exophthalmos progressed slightly during the first year of ERT, and then started to regress. Exposure conjunctivitis still bothered her currently.

The patient suffered from intermittent dyspnea at age 34 years. She became cyanotic and had an oxygen saturation of $85 \%$ as measured by pulse oximeter. Arterial blood gas analysis revealed a $\mathrm{pH}$ of 7.41 , carbon dioxide tension of $27.9 \mathrm{mmHg}$, and oxygen tension of $61.2 \mathrm{mmHg}$ in room air. A grade III/VI bruit was audible over the right lower chest, and a chest $\mathrm{x}$-ray revealed prominent pulmonary conus and increased infiltration over the right lower lung field (Fig. 1B). A high-resolution computed tomography (HRCT) of the chest suspected an AVM with engorged right inferior pulmonary artery and its draining veins (Fig. 1C); but no focal lesions were found in the lung paren- chyma. Right pulmonary artery angiogram showed several dilated and tortuous vessels from the right pulmonary artery, which directly connected to vessels draining into the right pulmonary vein over the right lower lobe of the lung (Fig. 1D). Early appearance of contrast medium in the right pulmonary vein indicated the presence of pulmonary arteriovenous malformation. The patient's pulmonary artery pressures were 48/19 mmHg (mean, 33 mmHg). Embolization was achieved with 6 coils, and resulted in a rise of oxygen saturation to $96 \%$, although residual shunt was still present. Unfortunately, two months later, dyspnea and cyanosis recurred, and her oxygen saturation dropped to $85 \%$ in room air. A pulmonary function test at that time revealed moderately severe restrictive lung disease.

\section{Discussion}

This 34-year-old patient presented symptoms and signs of exophthalmos and pulmonary AVM, which are unusual for Gaucher disease. She had normal mentality with no neurological symptoms such as ophthalmoplegia, therefore the disease could be classified as type I. However, she had severe thrombocytopenia requiring splenectomy and had had repeated fracture requiring prolonged immobilization. In a recent report from the Gaucher Registry, fracture was present in only $15 \%$ of all patients [9]. The patient's twin sister received splenectomy at young age and has bone disease similar to hers. Therefore, these sisters have an illness toward the severe end of the type I Gaucher disease.

Ocular manifestations in Gaucher disease are very rare, and the tissues reported to be involved are retina, conjunctive, and uvea [6-8]. In the MRI study, the increased retrobulbar spaces are filled with tissues with fat density, suggesting that the exophthalmos is caused by Gaucher cell infiltration. The clinical course also supports this hypothesis, since the patient's eyes started to retract after ERT.

Gaucher cells can infiltrate the alveolar spaces or the interlobular and intralobular septa, leading to air space and interstitial disease [2]. Gaucher cells can also plug in the pulmonary capillary vessels and cause pulmonary hypertension [10]. However, the chest x-ray and HRCT of the index patient revealed normal lung parenchyma, not suggesting direct alveolar or interstitial infiltration of Gaucher cells. It is also known that Gaucher disease can cause hepatic dysfunction which may induce abnormal dilatation of the intrapulmonary capillaries or the so-called hepatopulmonary syndrome $[4,5]$. It is possible that pulmonary AVM was the consequence of an abnormal progression of the hepatopulmonary syndrome, however, there was no overt evidence of severe hepatic dysfunction in the patient. 

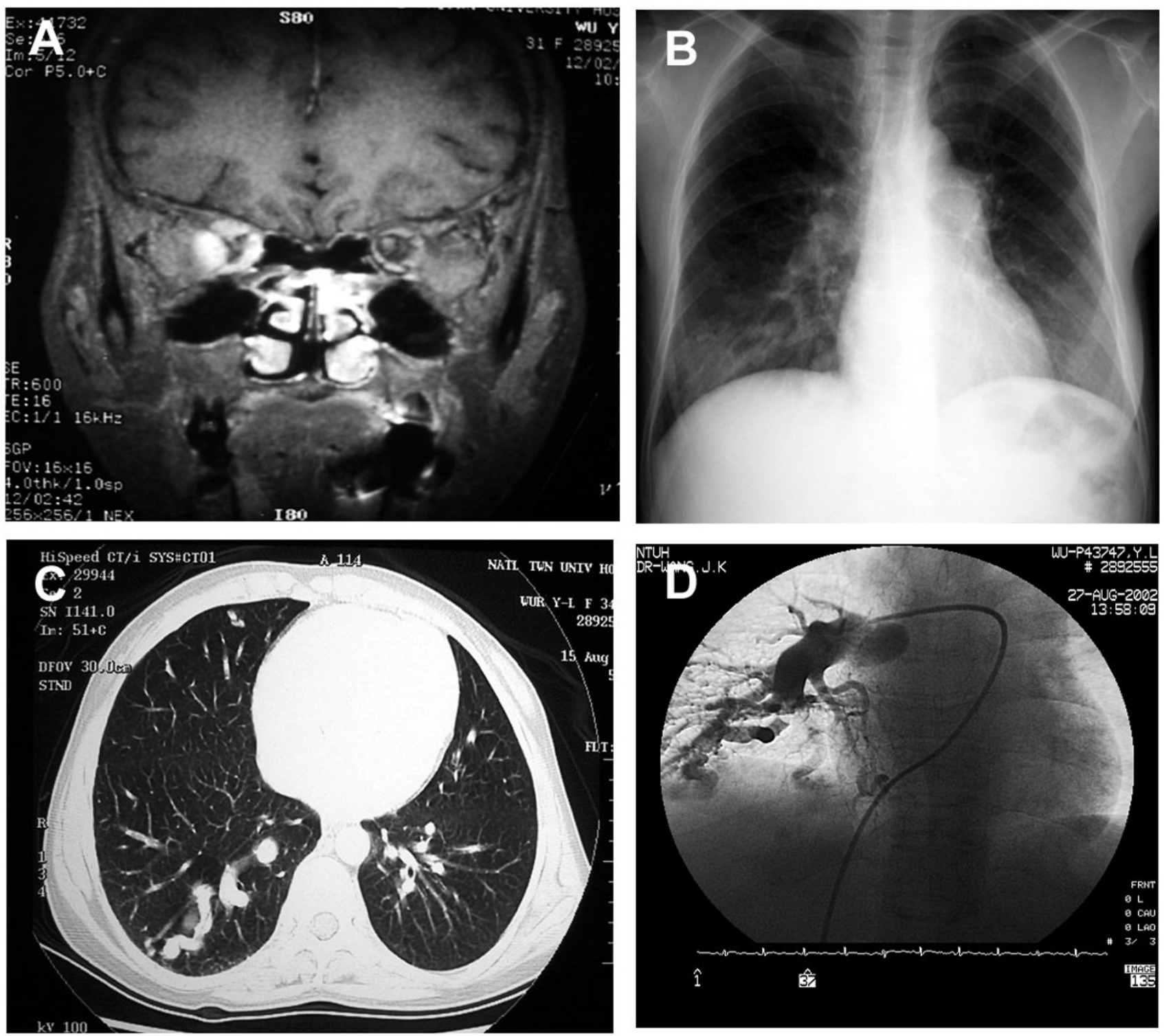

\section{Figure I}

Type I Gaucher disease with exophthalmos and pulmonary arteriovenous malformation. (A) MRI of the head shows increases in retrobulbar space and hypertrophy of extra-ocular muscles. (B) Chest $X$ ray reveals prominent pulmonary conus and increased infiltration over right lower lung field. (C) High-resolution computed tomography of chest reveals engorged right inferior pulmonary artery and its draining veins. (D) Pulmonary angiogram demonstrates right pulmonary arteriovenous malformation.

ERT has had a great impact on the outcome of Gaucher disease [11]. On the other hand, the effect of ERT on pulmonary hypertension remains to be established [12-15]. The patient had mild pulmonary hypertension. The pulmonary hypertension might not be related to AVM, since the latter condition usually causes low pulmonary artery pressure [16]. It has been reported that pulmonary hyper- tension may be triggered or aggravated by ERT [17]. It is possible that the pulmonary AVM may have existed but only caused symptoms when ERT changed intrapulmonary hemodynamics after clearance of Gaucher cells.

Through a registry of 1698 patients reported in 2000, the allele frequency of N370S was 53\%, and that of L444P 
was $18 \%$ [9]. The L444P mutation is more common in Asians [19,20], and has been detected in Taiwanese patients with both type I and II Gaucher disease [20,21]. The prevalence of L444P and the absence of the N370S mutation may explain the more severe phenotype in Gaucher disease in Asians. The V375L mutation has been classified as a mild mutation [22], which might explain the V375L/L444P genotype in type I Gaucher disease. However, although the twin sister of the indexed person had bone disease of similar severity, she didn't have eye or lung problem. One the contrary, their younger sister has less skeletal involvemen, but had dyspnea and cyanosis, which responded to ERT. There surely are non-allelic or epigenetic factors influencing the phenotypes.

\section{Conclusion}

Although both eye and lung diseases have been associated with Gaucher disease, this is the first reported demonstration of exophthalmos and pulmonary AVM in the same patient. This case may therefore present an extremely severe and unusual form of type I Gaucher disease. Different responses of these lesions to ERT would probably be attributed to different pathogenesis and natural course in the organ involvement in Gaucher disease.

\section{Competing interests}

The author(s) declare that they have no competing interests.

\section{Authors' contributions}

CC prepared the manuscript of this case report. YC and WH conducted long-term follow-up and prescribed ERT for the patients. NT and WZ carried out the gene mutation analysis. JW performed coil embolization of the pulmonary AVM. All authors read and approved the final manuscript.

\section{References}

I. Cotran RS, Kumar V, Robbins SL: Genetic disorders. In Pathologic Basis of Disease 5th edition. Edited by: Cotran RS, Kumar V, Robbins SL. Philadelphia: W. B. Saunders; 1994:143.

2. Amir G, Ron N: Pulmonary pathology in Gaucher's disease. Hum Pathol 1999, 30:666-70.

3. Kerem E, Elstein D, Abrahamov A, Bar Ziv Y, Hadas-Halpern I, Melzer $E$, Cahan C, Branski D, Zimran A: Pulmonary function abnormalities in type I Gaucher disease. Eur Respir J 1996, 9:340-5.

4. Dawson A, Elias DJ, Rubenson D, Bartz SH, Garver PR, Kay AC, Bloor CM, Beutler E: Pulmonary hypertension developing after alglucerase therapy in two patients with type I Gaucher disease complicated by the hepatopulmonary syndrome. Ann Intern Med 1996, I 25:90I-4.

5. Kim JH, Park CH, Pai MS, Hahn MH, Kim HJ: Hepatopulmonary syndrome in Gaucher disease with right-to-left shunt: evaluation and measurement using Tc-99m MAA. Clin Nucl Med 1999, 24:164-6.

6. Petrohelos M, Tricoulis D, Kotsiras I, Vouzoukos A: Ocular manifestations of Gaucher's disease. Am J Ophthalmol 1975, 80:1006-10.

7. Sasaki T, Tsukahara S: New ocular findings in Gaucher's disease: a report of two brothers. Ophthalmologica 1985, 191:206-9.
8. vom Dahl S, Niederau C, Haussinger D: Loss of vision in Gaucher's disease and its reversal by enzyme-replacement therapy. N Eng J Med 1998, 338: | 47 I-2.

9. Charrow J, Andersson HC, Kaplan P, Kolodny EH, Mistry P, Pastores G, Rosenbloom BE, Scott CR, Wappner RS, Weinreb NJ, Zimran A: The Gaucher registry: demographics and disease characteristics of 1698 patients with Gaucher disease. Arch Intern Med 2000, 160:2835-43.

10. Ross DJ, Spira S, Buchbinder NA: Gaucher cells in pulmonarycapillary blood in association with pulmonary hypertension. N Eng J Med 1997, 336:379-8I.

II. Hsu CC, Chien YH, Lai MY, Hwu WL: Enzyme replacement therapy with imiglucerase in Taiwanese patients with type I Gaucher disease. J Formos Med Assoc 2002, 101:627-31.

12. Harats D, Pauzner R, Elstein D, Many A, Klutstein MW, Kramer MR, Farfel Z, Zimran A: Pulmonary hypertension in two patients with type I Gaucher disease while on alglucerase therapy. Acta Haematol 1997, 98:47-50.

13. Pelini M, Boice D, O'Neil K, LaRocque J: Glucocerebrosidase treatment of type I Gaucher disease with severe pulmonary involvement. Ann Intern Med 1994, I 2 I: 196-7.

14. Mistry PK, Sirrs S, Chan A, Pritzker MR, Duffy TP, Grace ME, Meeker DP, Goldman ME: Pulmonary hypertension in type I Gaucher's disease: genetic and epigenetic determinants of phenotype and response to therapy. Mol Genet Metab 2002, 77:91-8.

15. Goitein O, Elstein D, Abrahamov A, Hadas-Halpern I, Melzer E, Kerem E, Zimran A: Lung involvement and enzyme replacement therapy in Gaucher's disease. QJ Med 200I, 94:407-I5.

16. Edell ES, Cortese DA, Krowka MJ, Rehder K: Severe hypoxemia and liver disease. Am Rev Respir Dis 1989, 140:1631-5.

17. Elstein D, Klustein MW, Lahad A, Abrahamov A, Hadas-Halpern I, Zimran A: Echocardiographic assessment of pulmonary hypertension in Gaucher's disease. Lancet 1998, 35 I:1544-6.

18. Rudzki Z, Okon K, Machaczka M, Rucinska M, Papla B, Skotnicki AB: Enzyme replacement therapy reduces Gaucher cell burden but may accelerate osteopenia in patients with type I disease - a histological study. Eur J Haematol 2003, 70:273-8I.

19. Eto $\mathrm{Y}$, Ida $\mathrm{H}$ : Clinical and molecular characteristics of Japanese Gaucher disease. Neurochem Res 1999, 24:207-II.

20. Choy FY, Humphries ML, Shi H: Identification of two novel and four uncommon missense mutations among Chinese Gaucher disease patients. Am J Med Genet 1997, 71:172-8.

21. Kim JW, Liou BB, Lai MY, Ponce E, Grabowski GA: Gaucher disease: identification of three new mutations in the Korean and Chinese (Taiwanese) populations. Hum Mutat 1996, 7:214-8.

22. Cormand B, Grinberg D, Gort L, Fiumara A, Barone R, Vilageliu L, Chabas A: Two new mild homozygous mutations in Gaucher disease patients: Clinical signs and biochemical analyses. $\mathrm{Am}$ J Med Genet 1997, 70:437-43.

\section{Pre-publication history}

The pre-publication history for this paper can be accessed here:

\section{http://www.biomedcentral.com/1471-2350/6/25/prepub}

Publish with Bio Med Central and every scientist can read your work free of charge

"BioMed Central will be the most significant development for disseminating the results of biomedical research in our lifetime. "

Sir Paul Nurse, Cancer Research UK

Your research papers will be:

- available free of charge to the entire biomedical community

- peer reviewed and published immediately upon acceptance

- cited in PubMed and archived on PubMed Central

- yours - you keep the copyright 